\title{
Quantitative Trait Loci for Health Traits in Finnish Ayrshire Cattle
}

\author{
N. F. Schulman, ${ }^{1}$ S. M. Viitala, ${ }^{1}$ D. J. de Koning, ${ }^{2}$ J. Virta, ${ }^{1}$ A. Mäki-Tanila, ${ }^{1}$ and J. H. Vilkki ${ }^{1}$ \\ ${ }^{1}$ MTT, Agrifood Research Finland, Animal Breeding, FIN-31600 Jokioinen, Finland \\ ${ }^{2}$ Department of Genetics and Biometry, Roslin Institute, Roslin, EH25 9P5 UK
}

\section{ABSTRACT}

A whole-genome scan was conducted to search for quantitative trait loci (QTL) affecting health traits in Finnish Ayrshire dairy cattle. The mapping population consisted of 12 bulls and their 491 sons in a granddaughter design. A total of 150 markers were typed covering all 29 autosomes. The traits under study were somatic cell score, mastitis, and a group of other veterinary treatments. Effects of the QTL and positions were estimated with the regression method. When carrying out interval mapping on each chromosome, cofactors were used to adjust for QTL identified at other chromosomes. Empirical $P$-values were obtained by permutation. Altogether 17 QTL were detected with genomewise significant $P$-values in the across family analysis. Quantitative trait loci affecting SCS were identified on chromosomes 1, 3, 11, 18, 21, 24, 27, 29, and QTL for mastitis on chromosomes 14, 18. Quantitative trait loci for other veterinary treatments were found on chromosomes $1,2,5,8,15,22$, and 23 . The allele substitution effects were from 0.5 to 1.7 genetic standard deviations. The positions of these health QTL did not overlap with milk QTL detected in previous studies of the same population.

(Key words: QTL, health, mastitis, dairy cow)

Abbreviation key: MAS = marker-assisted selection .

\section{INTRODUCTION}

Good health is essential for high production, longevity, and welfare of dairy cows. Diseases like mastitis and ketosis cause major costs to dairy farms. Economic losses are mainly due to reduced milk production and lowered milk quality but also to cost of veterinary treatments and of involuntary culling of cows. Impaired milk quality causes losses to the dairy industry.

Many countries have included maintenance and/or improvement of health in the breeding goal. Most com-

Received May 19, 2003

Accepted September 25, 2003.

Corresponding author: N. Schulman; e-mail: nina.schulman@ mtt.fi. mon is the use of SCC as an indicator trait for improving mastitis resistance. In the Nordic countries, veterinary records are available for a majority of cows. In Finland, health disorders diagnosed by veterinarians have been recorded since 1982.

Health traits are often difficult and expensive to measure. They have low heritability and are usually genetically antagonistic to production traits. The genetic correlations reported between mastitis and milk production or somatic cell score and milk production are moderate and positive (Emanuelson, 1988). Further, many of the health traits like mastitis, can be measured only in mature females. Genetic improvement of such traits would benefit from the use of marker information in selection decisions. (Lande and Thompson, 1990; Ruane and Colleau, 1996).

Several QTL mapping projects undertaken in recent years have mainly concerned production traits (Spelman et al., 1996; Arranz et al., 1998; Viitala et al., 2003). Putative QTL for health traits have been analyzed only in few studies. In most of the studies, health traits are limited to somatic cell score because information has been available only for this trait (Ashwell et al., 1997; Zhang et al., 1998; Schrooten et al., 2000). The only study on QTL affecting mastitis has been carried out in Norway (Klungland et al., 2001).

In an earlier study, Finnish Ayrshire cattle were used in a whole-genome scan to detect milk trait QTL (Viitala et al., 2003). The objective of the present study was to detect QTL areas associated with health traits in the same Ayrshire families.

\section{MATERIALS AND METHODS}

\section{Population and Traits}

For the study, 12 sires and 491 of their sons were used in a granddaughter design. The number of sons per sire ranged from 21 to 82 , with an average of 41 sons per sire. All sons were AI bulls of Finnish Ayrshire breed with an average of 497 daughter records per bull for SCS and 466 daughter records for mastitis treatments. Finnish AI stations provided semen samples. The phenotypic data used were breeding values obtained from the Finnish Animal Breeding Association from the fall 2000 evaluation. 
The analyzed traits were: SCS based on daughters' SCC transformed to a logarithmic scale; mastitis based on treatments for mastitis within $7 \mathrm{~d}$ before and $150 \mathrm{~d}$ after calving or on culling due to udder health problems; veterinary treatments that include all other veterinary treatments except those for mastitis and for fertility within $150 \mathrm{~d}$ of calving. The most frequent health disorders included in veterinary treatments were milk fever, ketosis, and retained placenta. The heritability estimates used in the national bull evaluation are: 0.15 for SCS, 0.05 for mastitis, and 0.03 for other veterinary treatments.

Breeding values were estimated using a repeatability model. Records from the first 3 lactations were used. This is justified because genetic correlations between different lactations have been shown to be moderate to high (Pösö and Mäntysaari, 1996). All bulls in the mapping population had daughters in all 3 lactations. A repeatability animal model was used for SCS and a repeatability sire model for mastitis and other veterinary treatments. Breeding values were based on lactation averages. Mastitis and other veterinary treatments were recorded as binary traits scored as 0 or 1 .

\section{Markers and Genotypes}

The bulls were genotyped for 148 microsatellite markers and 2 candidate genes affecting lactation. All together the markers covered all 29 autosomes of the bovine genome. Number of markers per chromosome varied from 2 to 14 . The average spacing between markers was $20 \mathrm{cM}$. Linkage maps were constructed using ANIMAP (Georges et al., 1995). The total length of the analyzed genome was $2764 \mathrm{cM}$. Polymorphic information content was calculated for each marker. The linkage map and polymorphic information content values are available at http://www.mtt.fi/julkaisut/cattleqtl.

The method of DNA extraction, PCR reaction protocols and electrophoresis have been described in previous studies (Vilkki et al., 1997; Elo et al., 1999).

\section{Statistical Analysis}

Quantitative trait loci were detected using a multiple marker regression approach (Knott et al., 1996; Vilkki et al., 1997). The test statistic was computed as an $F$ ratio. The analysis was done both across and within families. Association between markers and trait was first analyzed individually for each chromosome. To increase power of the interval mapping on each chromosome, QTL identified on other chromosomes were accounted for by fitting their transmission probabilities at the found positions as cofactors in the analysis (de Koning et al., 2001). Possible QTL from the initial anal- ysis of the individual chromosomes were chosen as cofactors if they exceeded the chromosomewise $10 \%$ significance threshold. This low threshold was chosen to avoid missing QTL areas. The same regions were then assessed with genomewise threshold for their significance as QTL. The QTL effects on all the chromosomes were reestimated jointly at the identified positions. Then each chromosome was reanalyzed using the phenotypes, which had been adjusted for the QTL effects on the rest of the genome. The steps were repeated until no new QTL were revealed. If an initially chosen QTL failed to reach the $10 \%$ chromosomewise significance threshold, later in the analysis it was dropped from subsequent repeats.

Significance thresholds and $P$-values for the test statistic were obtained by permutation (Churchill and Doerge, 1994). The permutation was repeated 10,000 times for each chromosome and trait separately. A Bonferroni correction was applied on these chromosomewise $P$-values in order to get genomewise $P$-values. The formula was: $P_{\text {genome }}=1-\left(1-P_{\text {chromosome }}\right)^{29}$, where 29 is the number of autosomes.

A 2-QTL model was fitted for those chromosomes that had more than 3 informative markers if one significant QTL had been detected and if the estimated QTL positions in the individual families indicated 2 different positions (Spelman et al., 1996; Velmala et al., 1999). With the 2-QTL model, the permutations were done to test 2 QTL vs. no QTL. If this result exceeded the nominal significance threshold of 5\%, the $P$-value for 2-QTL vs. 1-QTL was obtained from a standard F table. The degrees of freedom for the $\mathrm{F}$ statistic were the number of grandsires as numerator and total number of offspring minus 3 times the number of grandsires as denominator.

\section{RESULTS}

\section{Somatic Cell Score}

In the first stage where chromosomes were analyzed separately, QTL for SCS were located on chromosomes $3,11,14,18,27$, and 29 at $5 \%$ chromosomewise significance (Table 1). When putative QTL were added as cofactors to increase the statistical power, 10 QTL at $1 \%$ chromosomewise significance were detected. Of these, 8 QTL reached $1 \%$ genomewise significance (Table 1). The total additive genetic variance explained by the 10 cofactors was $45 \%$. The 2-QTL model was not fitted for SCS because there was no indication of 2 separate QTL positions on the same chromosome.

In the QTL analysis within families using cofactors, the most significant QTL ( $P$ chromosomewise between 0.01 and 0.0001 ) were detected on chromosomes 1,3 , and 29. Confidence intervals for the observed QTL posi- 
Table 1. The locations and significance levels of somatic cell score QTL found with a granddaughter design in Finnish Ayrshire cattle.

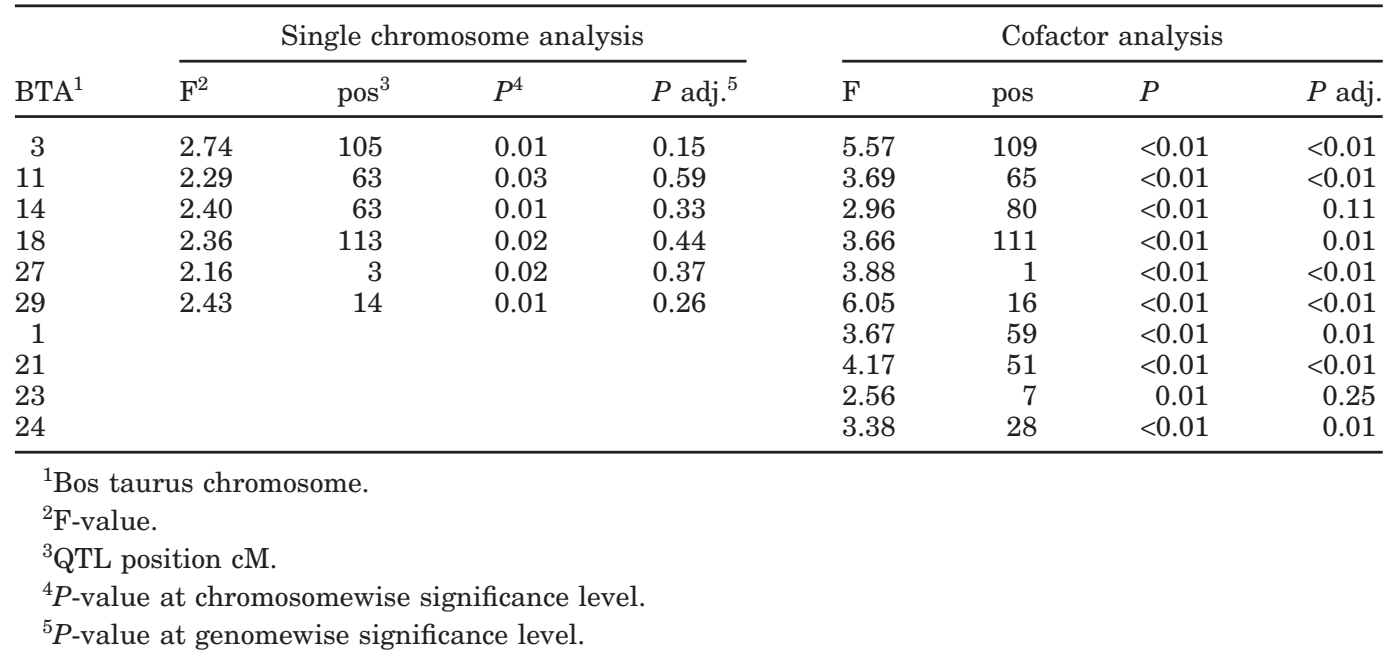

tions were not computed in this study, but based on previous studies of the same population they would be large. The QTL positions mentioned in this text refer to the position of the highest $F$-value on the chromosome. For chromosome 1, 2 families had significant $F$ values. The QTL positions for both of these families were close to marker TGLA57. For chromosome 3, 2 families had their QTL position close to marker HUJ1177. The same allele at this marker seems to be associated with unfavorable SCS values in both families. This association has not been tested at the population level. For chromosome 29, 2 families had a significant QTL close to marker ILSTS057. In a third family the QTL position was closer to marker BMC8012. The number of families per chromosome with chromosomewise significant QTL ranged from 2 to 4 . In most cases the QTL positions of the individual families were close to the same markers. The allele substitution effects ranged from 0.5 to 1.7 standard deviations of EBV.

\section{Mastitis}

In the initial analysis without cofactors a QTL for mastitis was detected on chromosome 18 at chromosomewise 5\% significance. When cofactors were added, 5 QTL were detected at 5\% chromosomewise significance. The QTL on chromosomes 14 and 18 reached genomewise significance (Table 2). The total additive genetic variance explained by the 5 cofactors was $23 \%$. The 2-QTL model was not fitted for mastitis because there was no indication of 2 separate QTL positions in any of the families.

On chromosome 18, 3 families had significant $F$-values ( $P$ chromosomewise between 0.03 and 0.0001 ) in the analysis within families. The positions were close to marker TGLA227. On chromosome 14, 2 families had significant $F$-values ( $P$ chromosomewise 0.02 and 0.001). The QTL positions were between markers BMS1747 and RM011 for one family, and between RM011 and BMS740 for the other. On the other 3 chromosomes $(10,11,21)$ that had significant QTL at chromosomewise level only, 1 or 2 families were involved. The allele substitution effects of the identified QTL ranged from 0.7 to 1.4 standard deviations of EBV.

On chromosomes 18,14 , and 11 , there was some indication of QTL for both SCS and mastitis. At chromosome 18 the QTL for both SCS and mastitis were located at the same position in the across family analysis at the distal end of the chromosome close to marker TGLA227 (Figure 1). Five families were involved but only one family was significant for both QTL. The same allele seems to be associated with unfavorable EBV in both traits. At chromosome 14, with a genomewise significant QTL for mastitis and a chromosomewise significant QTL for SCS, the QTL locations were at different ends of the chromosome in the across family analysis (Figure 2). Only one family showed some evidence for both QTL, but the areas were not overlapping. At chromosome 11, with a genomewise significant QTL for SCS and a chromosomewise significant QTL for mastitis, the positions were quite different in the across family analysis. On this chromosome, the individual families showed different positions within the traits as well as between the traits (Figure 3). There were 4 significant families; both QTL could be detected in one family.

\section{Other Veterinary Treatments}

When chromosomes were analyzed separately for other veterinary treatments, chromosomes $2,14,16$, 
Table 2. Locations and significance levels of mastitis QTL found with a granddaughter design in Finnish Ayrshire cattle.

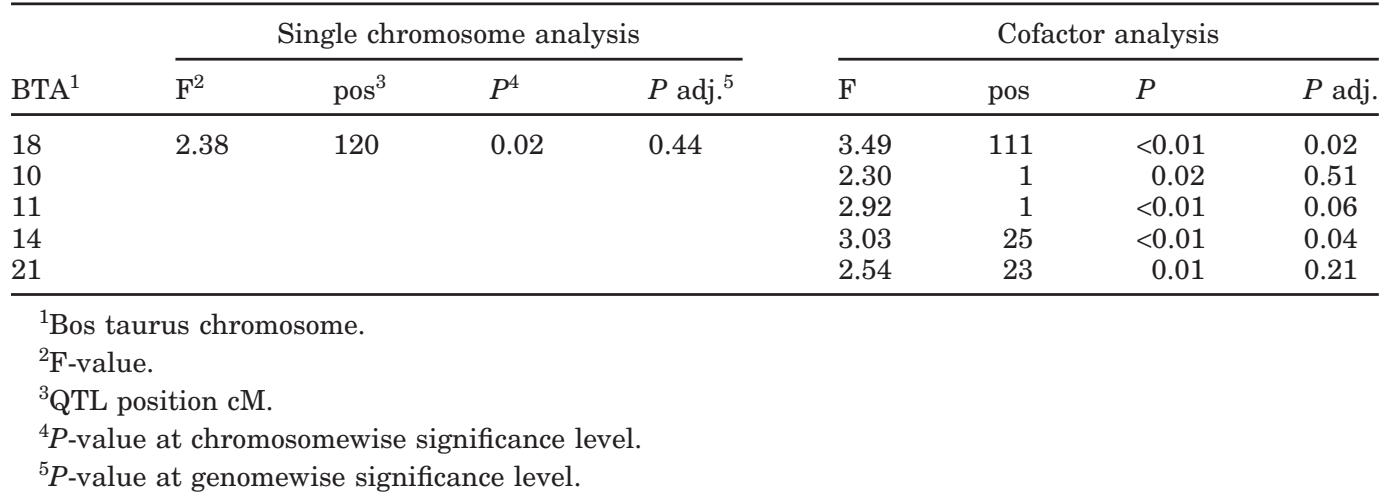

and 22 showed QTL areas at chromosomewise significance, and a QTL on chromosome 23 approached genomewise significance. When cofactors were used in the analysis, 7 QTL exceeding the genomewise 1\% threshold were indicated (Table 3), while the QTL on chromosomes 14 and 16 were not supported. The total additive genetic variance explained by the joint 7 cofactors was $38 \%$. The further analysis did not show evidence for 2 QTL on any of the analyzed linkage groups.

The analysis within families showed that the QTL from the across-family analysis were segregating in 2 to 5 families per chromosome. Chromosomes 2 and 15 had the most significant within family F-values. For chromosome 2 the location was close to URB42 in one family. In the other 3 families showing QTL on that chromosome, the location of the highest test statistic was in the distal area of the chromosome. On chromo-

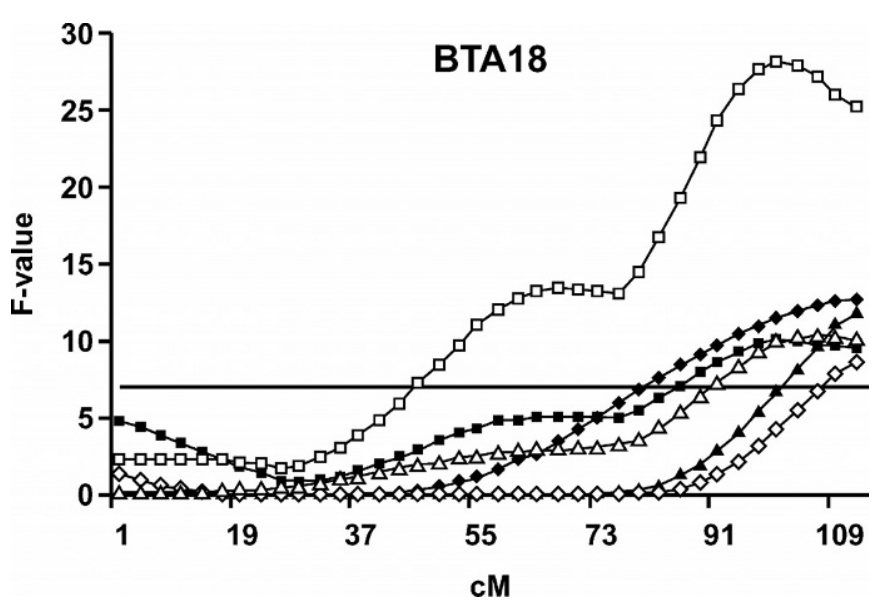

Figure 1. Profiles of test statistics for chromosome 18 from analysis within families. Quantitative trait loci for somatic cell score (SCS) were detected in families $1(\boldsymbol{)}), 8(\mathbf{\Delta})$, and $10(\mathbf{\square})$. Quantitative trait loci for mastitis were detected in families $4(\diamond), 5(\triangle)$, and $10(\square)$. The value of the $\mathrm{F}$-statistic exceeded the $5 \%$ chromosomewise significance threshold (-) in all families. some 15 , the family with the most significant $F$-value indicated the QTL location to be between markers NCAM and BR3510, while the location supported by the other 2 families was between markers BR3510 and MGTG13B. On chromosome 23 the QTL location was at BOLA-DRBP1 for one family, whereas the best position in the other family was at BM1258. The effects of the QTL ranged from 0.6 to 1.4 standard deviations of EBV.

\section{DISCUSSION}

A whole-genome scan was carried out to map health trait QTL in Finnish Ayrshire cattle. When chromosomes were analyzed separately, 6 chromosomewise significant QTL for SCS and 1 for mastitis were detected. When the power of the analysis was increased

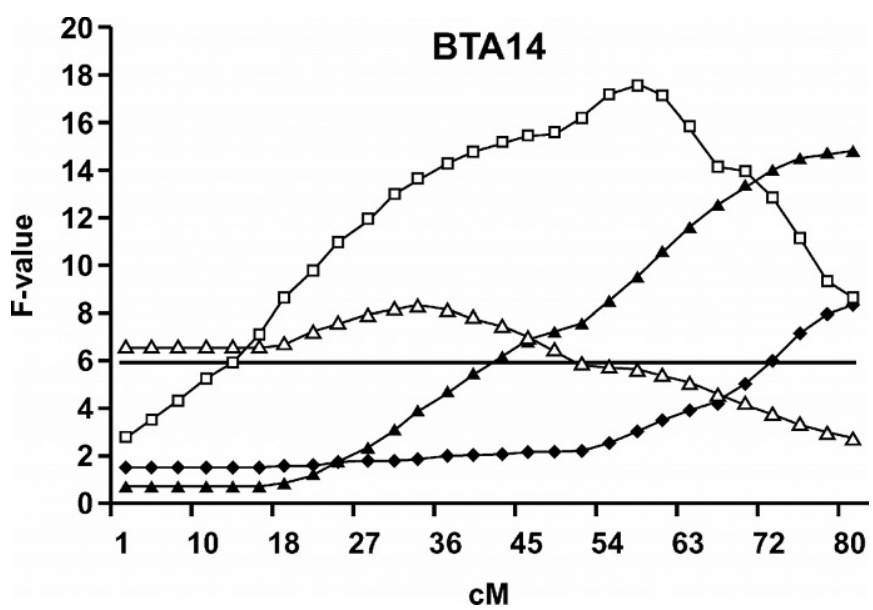

Figure 2. Profiles of test statistics for chromosome 14 from analysis within families. Quantitative trait loci for somatic cell score (SCS) were detected in families $2(\diamond)$, and $7(\boldsymbol{\Lambda})$. Quantitative trait loci for mastitis were detected in families $7(\triangle)$ and $12(\square)$. The value of the F-statistic exceeded the 5\% chromosomewise significance threshold (-) in all families. 


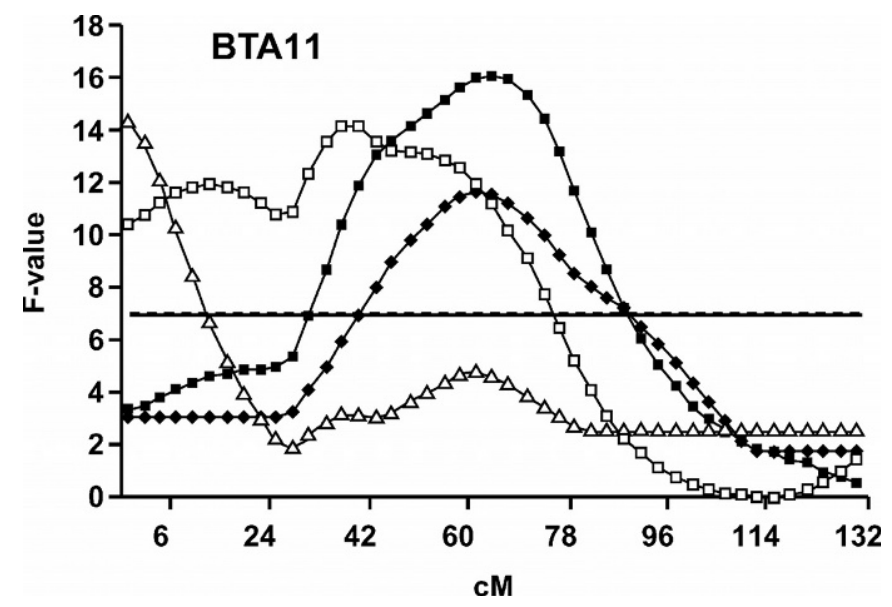

Figure 3. Profiles of test statistics for chromosome 11 from analysis within families. Quantitative trait loci for somatic cell score (SCS) were detected in families $3(\bullet)$ and $12(\square)$. Quantitative trait loci for mastitis were detected in families $5(\triangle)$ and $12(\square)$. The value of the F-statistic exceeded the $5 \%$ chromosomewise significance threshold (-) in all families.

by fitting possible QTL positions as cofactors, a total of 17 genomewise significant QTL for udder health traits were detected. For other veterinary treatments, which include all other treatments for diseases than udder or fertility, 4 QTL were found at chromosomewise significance and one at chromosome 23 close to genomewise significance, when chromosomes were analyzed separately. Adding cofactors revealed 7 genomewise significant QTL for this complex trait. Two of the five QTL found without cofactors were not detected when cofactors were used. This could be due to false positives in the analysis without cofactors. For a chromosomewise level of 5\% significance 1.5 false positives would be expected. The QTL on chromosome 23 has already been detected in the same population in an earlier study (Elo et al., 1999).

Only few families contributed to the results for different chromosomes. In some families many QTL were detected and in some only few if any. This could be due to the family history or the cofactor method where the power is increased for detection of a second QTL when one has already been detected. The family size did not seem to affect the number of QTL detected.

On chromosome 18, genomewise significant QTL for both SCS and mastitis were located at the same position at the distal end of the chromosome. There were 5 families involved and in one of these both QTL were detected. In 4 families the same allele at marker TGLA227 was associated with unfavorable values of SCS and/ or mastitis. Three of these families share a common ancestor. Further studies will be carried out to test the association at the population level. At chromosome 11, there was some indication of 2 separate QTL positions, one for SCS and one for mastitis. A multitrait analysis of the data may give more information to this question. Moderate genetic correlations have been reported for SCS and mastitis in the Finnish Ayrshire (Pösö and Mäntysaari, 1996). The correlations varied from 0.37 for first lactation to 0.68 for third lactation.

Some other studies have mapped QTL for SCS, mastitis, or both (Table 4). In most of them the mapping population has consisted of Holstein bulls in a granddaughter design. Most of the reported QTL are only nominally significant. On chromosomes 3 and 18 the QTL affecting SCS and mastitis are located in the same area, in the distal end of the chromosome. On chromosome 23, all reported QTL are located at the proximal end. The QTL areas indicated on chromosomes 1, 14, 21 and 27 differ considerably between studies.

Table 3. Locations and significance levels of QTL for other veterinary treatments found with granddaughter design in Finnish Ayrshire cattle.

\begin{tabular}{|c|c|c|c|c|c|c|c|c|}
\hline \multirow[b]{2}{*}{$\mathrm{BTA}^{1}$} & \multicolumn{4}{|c|}{ Single chromosome analysis } & \multicolumn{4}{|c|}{ Cofactor analysis } \\
\hline & $\mathrm{F}^{2}$ & $\operatorname{pos}^{3}$ & $P^{4}$ & $P$ adj. ${ }^{5}$ & $\mathrm{~F}$ & pos & $P$ & $P$ adj. \\
\hline 2 & 2.44 & 51 & 0.04 & 0.65 & 4.82 & 28 & $<0.01$ & $<0.01$ \\
\hline 14 & 2.72 & 51 & 0.01 & 0.21 & & & & \\
\hline 16 & 2.48 & 67 & 0.01 & 0.25 & & & & \\
\hline 22 & 2.50 & 5 & 0.01 & 0.30 & 4.18 & 1 & $<0.01$ & $<0.01$ \\
\hline 23 & 3.13 & 38 & $<0.01$ & 0.05 & 4.46 & 22 & $<0.01$ & $<0.01$ \\
\hline 1 & & & & & 4.52 & 22 & $<0.01$ & $<0.01$ \\
\hline 5 & & & & & 3.80 & 76 & $<0.01$ & 0.01 \\
\hline 8 & & & & & 3.60 & 121 & $<0.01$ & $<0.01$ \\
\hline 15 & & & & & 3.96 & 101 & $<0.01$ & 0.01 \\
\hline
\end{tabular}


Table 4. Results from studies on quantitative trait loci detection for SCS and mastitis.

\begin{tabular}{|c|c|c|c|c|}
\hline \multirow[b]{2}{*}{ Chromosome } & \multicolumn{2}{|c|}{ Somatic cell score } & \multicolumn{2}{|c|}{ Mastitis } \\
\hline & Authors $^{1}$ & Markers & Authors $^{1}$ & Markers \\
\hline \multirow[t]{2}{*}{1} & 8 & TGLA57 & & \\
\hline & 6 & MAF46 & & \\
\hline \multirow[t]{2}{*}{3} & 8 & HUJ1177 & 4 & BR4502 \\
\hline & 7 & BMC5227 & & \\
\hline \multirow[t]{3}{*}{14} & 8 & BM4513 & 8 & BMS1747-BMS740 \\
\hline & 9 & ILSTS11-BM302 & 4 & BM6425 \\
\hline & 1 & BM302 & & \\
\hline \multirow[t]{4}{*}{18} & 8 & TGLA227 & 8 & TGLA227 \\
\hline & 5 & TGLA227 & & \\
\hline & 1 & BM2078 & & \\
\hline & 7 & BM7109-ILSTS002 & & \\
\hline \multirow[t]{3}{*}{21} & 8 & INRA103-TGLA122 & 8 & RM151-INRA103 \\
\hline & 2 & TGLA122 & & \\
\hline & 3 & ETH131 & & \\
\hline \multirow[t]{5}{*}{23} & 8 & CSSM005-RM033 & & \\
\hline & 2 & RM033 & & \\
\hline & 6 & RM033 & & \\
\hline & 1 & 513, BM1258 & & \\
\hline & 3 & MGTG7 & & \\
\hline \multirow[t]{2}{*}{27} & 8 & BMS641 & 4 & BM1857, INRA27 \\
\hline & 5 & BM3507-TGLA179 & & \\
\hline
\end{tabular}

\footnotetext{
${ }^{1} 1$ = Ashwell et al. 1997, 2 = Boichard et al. 2003, 3 = Heyen et al. 1999, 4 = Klungland et al. 2001, $5=$ Kühn et al. 2003, 6 = Reinsch et al. 1998, $7=$ Schrooten et al. 2000, $8=$ present study, $9=$ Zhang et al. 2000 .
}

Udder health disorders and milk yield are often reported to be unfavorably correlated genetically (Emanuelson, 1988; Pösö and Mäntysaari, 1996). Dairy cows with high milk production are more likely to get mastitis than cows with moderate or low production. In order to stop the decline in udder health due to selection for milk yield, SCS has been included in the breeding goal in many countries. In an earlier study of the same population (Viitala et al., 2003), some milk yield QTL were detected on chromosomes where SCS QTL now were indicated. However, the positions for the milk QTL and SCS QTL are different and the QTL are segregating in different families. The unfavorable correlation could be explained by the fact that not all QTL for either trait were detected. It seems that the QTL areas for milk yield and udder health found in this study are not overlapping and they could be exploited independently in marker-assisted selection (MAS) programs.

The trait called other veterinary treatments in this study is a complex trait that includes treatment records for many diseases. From the present data it is not possible to know with which of the diseases a certain QTL is associated within a family. Because milk fever (9.8\%), ketosis $(3.5 \%)$, and retained placenta $(2.4 \%)$ were the most common disorders registered in this group of the health-recording scheme, it is probable that the QTL detected are affecting these traits. In comparison, incidence of mastitis was $27.9 \%$ and fertility treatments $21.2 \%$ of all veterinary treatments (Rautala, 2001). Fur- ther studies are needed in order to use this QTL information in breeding for disease resistance. The treatment records of the families may allow distinguishing which particular disease is affected by the QTL.

\section{CONCLUSIONS}

Several QTL for health traits were identified in the study. Given the low heritabilities and difficulties in measurement of most of these traits, use of QTL information in breeding strategies like MAS would potentially be advantageous and speed up genetic improvement of these economically important health traits. In addition to economic advantages, animal welfare would be improved with these new tools in selecting for better health of dairy cattle also. Since the grandsires used in this study were born in the early seventies and eighties, the segregation of the QTL alleles in these families cannot directly be utilized for breeding purposes. Additional studies with more families and fine mapping of interesting QTL areas are needed.

\section{ACKNOWLEDGMENTS}

We would like to thank Anneli Virta for the electrophoresis runs of the microsatellites, Jukka Pösö from the Finnish Animal Breeding Association for providing the EBV of the bulls, and the AI stations for semen samples. The Finnish Ministry of Agriculture and Forestry, project number 310026, supported the study. 


\section{REFERENCES}

Arranz, J.-J., W. Coppieters, P. Berzi, N. Cambisano, B. Grisart, L. Karim, F. Marcq, L. Moreau, C. Mezer, J. Riquet, P. Vanmanshoven, D. Wagenaar, and M. Georges. 1998. A QTL affecting milk yield and composition maps to bovine chromosome 20: A confirmation. Anim. Genet. 29:107-115.

Ashwell, M. S., C. E. Rexroad, Jr., R. H. Miller, P. M. van Raden, and Y. Da. 1997. Detection of loci affecting milk production and health traits in an elite US Holstein population using microsatellite markers. Anim. Genet. 28:216-222.

Boichard, D., C. Grohs, F. Bourgeois, F. Cerqueira, R. Faugeras, A. Neau, R. Rupp, Y. Amigues, M. Y. Boscher, and H. Leveziel. 2003. Detection of genes influencing economic traits in three French dairy cattle breeds. Genet. Sel. Evol. 35:77-101.

Churchill, G. A., and R. W. Doerge. 1994. Empirical threshold values for quantitative trait mapping. Genetics 138:963-971.

de Koning, D. J., N. F. Schulman, K. Elo, S. Moisio, R. Kinos, J. Vilkki, and A. Mäki-Tanila. Mapping of multiple quantitative trait loci by simple regression in half-sib designs. 2001. J. Anim. Sci. 79:616-622.

Elo, K. T., J. Vilkki, D. J. de Koning, R. J. Velmala, and A. V. MäkiTanila. 1999. A quantitative trait locus for live weight maps to bovine chromosome 23. Mammalian Gen. 10:831-835.

Emanuelson, U. 1988. Recording of production diseases in cattle and possibilities for genetic improvements: A review. Livest. Prod. Sci. 20:89-106.

Georges, M., D. Nielsen, M. Mackinnon, A. Mishra, R. Okimoto, A. T. Pasquino, L. S. Sargeant, A. Sorensen, M. R. Steele, and X. Zhao. 1995. Mapping quantitative trait loci controlling milk production in dairy cattle exploiting progeny testing. Genetics 139:907-920.

Heyen, D. W., J. I. Weller, M. Ron, M. Band, J. E. Beever, E. Feldmesser, Y. Da, G. R. Wiggans, P. M. VanRaden, and H. A. Lewin. 1999. A genome scan for QTL influencing milk production and health traits in dairy cattle. Physiol. Genomics 1:165-175.

Klungland, H., A. Sabry, B. Heringstad, H. G. Olsen, L.Gomez-Raya, D. I. Våge, I. Olsaker, J. OØdegård, G. Klemetsdal, N. F. Schulman, J. Vilkki, J. Ruane, M. Aasland, K. Rønningen, and S. Lien. 2001. Quantitative trait loci affecting clinical mastitis and somatic cell count in dairy cattle. Mammalian Genet. 12:837-842.

Knott, S. A., J. M. Elsen, and C. S. Haley. 1996. Methods for multiplemarker mapping of quantitative trait loci in half-sib populations. Theor. Appl. Genet. 93:71-80.
Kühn, C., J. Bennewitz, N. Reinsch, N. Xu, H. Thomsen, C. Looft, G. A. Brockmann, M. Schwerin, C. Weimann, S. Hiendleder, G. Erhardt, I. Medjugorac, M. Förster, B. Brenig, F. Reinhardt, R. Reents, I. Russ, G. Averdunk, J. Blümel, and E. Kalm. 2003. Quantitative trait loci mapping functional traits in the German Holstein cattle population. J. Dairy Sci. 86:360-368.

Lande, R., and R. Thompson.1990. Efficiency of marker-assisted selection in the improvement of quantitative traits. Genetics 124:743-756.

Pösö, J., and E. A. Mäntysaari. 1996. Relationships between clinical mastitis, somatic cell score, and production for the first three lactations of Finnish Ayrshire. J. Dairy Sci. 79:1284-1291.

Rautala, H. 2001. Terveystarkkailun tulokset 2000. Nauta 31:22-23.

Reinsch, N., N. Xu, H. Thomssen, C. Looft, E. Kalm, S. Grupe, C. Kuhn, M. Schwerin, B. Leyhe, S. Hiendleder, G. Erhard, I. Medjugorac, I. Russ, M. Foster, B. Brenig, R. Reents, and G. Averdunk. 1998. First results on somatic cell count loci from the ADR bovine mapping project. Proc. 6th World Congr. Genet. Appl. Livest. Prod., Armidale, Australia 26:426-428.

Ruane, J., and J. J. Colleau. 1996. Marker assisted selection for a sex-limited character in a nucleus breeding population. J. Dairy Sci. 79:1666-1678.

Schrooten, C., H. Bovenhuis, W. Coppieters, and J. A. van Arendonk, J. A. 2000. Whole genome scan to detect quantitative trait loci for conformation and functional traits in dairy cattle. J. Dairy Sci. 8:795-806.

Spelman, R. J., W. Coppieters, L. Karim, J. A. van Arendonk, and H. Bovenhuis. 1996. Quantitative trait loci analysis for five milk production traits on chromosome six in the Dutch HolsteinFriesian population. Genetics 144:1799-1808.

Velmala R. J., H. J. Vilkki, K. T. Elo, D. J. de Koning, and A. V. Mäki-Tanila. 1999. A search for quantitative trait loci for milk production traits on chromosome 6 in Finnish Ayrshire cattle. Anim. Genet. 30:136-143.

Viitala, S. M., N. F. Schulman, D. J. de Koning, K. Elo, R. Kinos, A.Virta, J. Virta, A. Mäki-Tanila, and J. H. Vilkki. 2003. Quantitative trait loci affecting milk production traits in Finnish Ayrshire dairy cattle. J. Dairy Sci. 86:1828-1836.

Vilkki H. J., D. J. de Koning, K. Elo, R. Velmala, and A. Mäki-Tanila. 1997. Multiple marker mapping of quantitative trait loci of Finnish dairy cattle by regression. J. Dairy Sci. 80:198-204.

Zhang, Q., D. Boichard, I. Hoeschele, C. Ernst, A. Eggen, B. Murkve, M. Pfister Genskow, L. A.Witte, F. E. Gringola, P. Uimari, G. Thaller, and M. D. Bishop 1998. Mapping quantitative trait loci for milk production and health of dairy cattle in a large outbred pedigree. Genetics 149:1959-1973. 